\title{
Effect of GM6001 on the expression of syndecan-1 in rats with acute kidney injury and its protective effect on the kidneys
}

\author{
KUNYING ZHANG ${ }^{1}$, RONGXIN LI $^{2}$, GUODONG XU ${ }^{3}$, HUIRONG HAN $^{4}$ and LILI QIN ${ }^{1}$ \\ ${ }^{1}$ Department of Nephrology, Weifang People's Hospital, Weifang, Shandong 261000; ${ }^{2}$ Department of Pharmacy, \\ Affiliated Hospital of Weifang Medical University, Weifang, Shandong 261031; ${ }^{3}$ Department of Pathology, \\ Weifang People's Hospital, Weifang, Shandong 261000; ${ }^{4}$ Department of Anesthesiology, \\ Weifang Medical University, Weifang, Shandong 261042, P.R. China
}

Received November 7, 2019; Accepted December 3, 2019

DOI: $10.3892 / \mathrm{etm} .2020 .8892$

\begin{abstract}
Expression of syndecan-1 (SDC-1) in rats with acute kidney injury and the protective effect of GM6001 on the kidney were investigated. Fifty SD rats were selected and randomly divided into control group $(\mathrm{CG})(\mathrm{n}=15)$, treatment control group (TCG) $(n=10)$, module group $(\mathrm{MG})(\mathrm{n}=15)$ and treatment group (TG) $(n=10)$. In TG, the model of acute renal injury (AKI) in rats was established after pretreatment of intraperitoneal injection of GM6001 one day before modeling. In MG, the same amount of saline was injected intraperitoneally one day before modeling and the same treatment was done on the day of modeling. In CG, the same amount of saline was injected intraperitoneally one day before modeling but the model was not made. In TCG, rats were pretreated with intraperitoneal injection of GM6001 one day before modeling but the model was not made. The contents of blood urea nitrogen (BUN) in serum, serum creatinine (SCR), uric acid (UA) and blood $\beta 2$-microglobulin $(\beta 2-\mathrm{MG})$ were detected by ELISA. The content of SDC-1 in renal tissues was detected by qRT-PCR and western blotting. Expression of SDC-1 in renal tissue of 24 rats after modeling was lower than that of $\mathrm{MG}(\mathrm{P}<0.050)$. SDC-1 expression was the highest in $\mathrm{TG}(\mathrm{P}<0.05)$. Compared with before modeling, the contents of BUN, SCR, UA and $\beta 2-\mathrm{MG}$ in $\mathrm{MG}$ and $\mathrm{TG}$ increased $(\mathrm{P}<0.05)$. After modeling, the contents of serum BUN, SCR, UA and $\beta 2-\mathrm{MG}$ in TG were significantly lower than those in $\mathrm{MG}(\mathrm{P}<0.05)$. The levels of SDC-1 in renal tissue of rats with acute kidney injury increased. After GM6001 treatment, SDC-1 levels can be improved and has a certain protective effect on the kidneys.
\end{abstract}

Correspondence to: Dr Lili Qin, Department of Nephrology, Weifang People's Hospital, 151 Guangwen Street, Kuiwen, Weifang, Shandong 261000, P.R. China

E-mail: qlkaf9@163.com

Key words: syndecan-1, acute kidney injury, rat model, GM6001

\section{Introduction}

Acute kidney injury (AKI) is a life-threatening disease syndrome characterized by rapid loss of renal excretion function (1). This serious complication often occurs in critically ill patients with devastating consequences (2). Dialysis is an important choice for the treatment of acute renal failure in clinical treatment, but maintenance of dialysis leads to a higher daily medicine burden and peritoneal dialysis patients are at great risk of infection (3). At present, many drugs used for preventing and treating AKI have shown benefits in clinical models, but there is no specific drug for a curative effect in treatment of humans (4). The drug treatment of acute kidney injury needs further investigation.

Syndecan-1 (SDC-1) is a ubiquitous and multifunctional extracellular matrix proteoglycan, which can mediate the binding and activity of basic fibroblast growth factor (bFGF) and plays an important role in cell adhesion and maintenance of epithelial integrity (5). Lu et al (6) confirmed that ischemic AKI can be effectively prevented by inhibiting shedding of SDC-. Junior et al (7) also found that SDC-1 is a new biomarker for renal injury and endothelial dysfunction in HIV patients. The abscisic enzymes of matrix metalloproteinase (MMP) 7 (8), MP9 (9) and other SDC-1 proteases participate in the proteolysis of SDC-1 extracellular domain. GM6001 is a broad-spectrum MMP inhibitor (10), which acts on MMP-1, MMP-2, MMP-3 and MMP-8. It was considered that the application of GM6001 can reduce the proteolysis of SDC-1 by inhibiting the expression of MMPs, thus achieving the purpose of inhibiting SDC-1 to treat or prevent the development of AKI and effectively protect renal tissues of patients.

In this study, the expression of SDC-1 in the kidney tissues of rats was detected after the application of GM6001 to explore the protective effect of GM6001 on SDC-1 and kidney by establishing the rat model of acute kidney injury.

\section{Materials and methods}

Animals. Fifty clean grade 2 week-old SD rats, weighing 180-250 g, were purchased from Kay Biological Technology (Shanghai) Co., Ltd. The rats were raised at the temperature of $24.00 \pm 2.00^{\circ} \mathrm{C}$, humidity $50.00 \pm 5.00 \%$, natural light, free access 
to food and drink. The experiment was approved by the animal ethics committee of Weifang People's Hospital (Weifang, China).

\section{Methods}

Experimental methods. The rats after adaptive feeding were randomly assigned as CG $(\mathrm{n}=15)$, TCG $(\mathrm{n}=10)$, MG $(\mathrm{n}=15)$ and TG $(\mathrm{n}=10)$. Modeling method: Rats were anesthetized with phenobarbital. Bilateral renal arteries and renal veins were bluntly separated through the abdominal median incision. Bilateral renal arteries were clamped with non-invasive vascular clamps. The vascular clamps were loosened after $1 \mathrm{~h}$. Renal artery blood flow was restored and abdomen was closed layer by layer. Then the other groups of rats were treated: In TG, after pretreatment of intraperitoneal injection of GM6001 one day before modeling, the kidney injury model of rats was established according to the above method on the day of modeling. In MG, the same amount of saline was injected intraperitoneally one day before modeling and the same treatment was done on the day of modeling. In CG, the same amount of saline was injected intraperitoneally one day before modeling but the model was not made on the day of modeling. In TCG, rats were pretreated with intraperitoneal injection of GM6001 one day before modeling and the model was not made on the day of modeling. The contents of blood urea nitrogen (BUN), serum creatinine (SCR), uric acid (UA) and blood $\beta 2$-microglobulin ( $\beta 2-\mathrm{MG}$ ) in the above four groups were detected, respectively, before modeling and $24 \mathrm{~h}$ after successful modeling. All rats were sacrificed and the kidney tissues of the rats were stripped off. One piece of tissue was taken from each part and placed in $10 \%$ neutral formaldehyde at $4^{\circ} \mathrm{C}$ overnight for fixation to detect the contents of SDC- 1 in kidney tissue.

\section{Samples detection}

QRT-PCR: Detection of the contents of renal serum SDC-1. The collected serum was accelerated to coagulate, left to stand for $30 \mathrm{~min}$ and centrifuged at $4^{\circ} \mathrm{C}$ for $5 \mathrm{~min}$ at $400 \mathrm{x} \mathrm{g}$. The serum was taken and stored in a $1.5 \mathrm{ml}$ centrifuge tube in a refrigerator at $-80^{\circ} \mathrm{C}$ for testing. Total RNA was extracted. The concentration and purity of the extracted RNA were determined by using an ultraviolet spectrophotometer. The A260/A280 ratio should be between 1.8 and 2.1. The RNA concentration was calculated for further experiments. Then TransScript Green miRNA Two-Step qRT-PCR SuperMix was used for reverse transcription into cDNA. After the reaction, the cDNA sample was used as the template of qRT-PCR (Thermo Fisher Scientific - CN) reaction and put into the refrigerator for testing. The reaction conditions were cDNA $1 \mu \mathrm{l}$, forward primer $0.4 \mu \mathrm{l}$, Universal miRNA qPCR Primer $0.4 \mu 1,2 \mathrm{X}$ TransStart Tip Green qPCR SuperMix $10 \mu 1$, Passive Reference Dye (50X) (Optional) $0.4 \mu 1$ and total volume $20 \mu 1$. $\mathrm{ddH}_{2} \mathrm{O}$ was used to complete to $20 \mu \mathrm{l}$. The conditions were as follows: pre-denaturation at $95^{\circ} \mathrm{C}$ for $5 \mathrm{~min}$, then denaturation at $90^{\circ} \mathrm{C}$ for $15 \mathrm{sec}$, annealing and extension at $60^{\circ} \mathrm{C}$ for $30 \mathrm{sec}$ and the cycle was repeated 40 times. The relative expression of SDC-1 was expressed by $2^{-\Delta C t}$. All the tests were repeated 3 times and the results were averaged (Table I).

Western blotting: Detection of the contents of SDC-1 in kidney tissue. After the collected rat kidney tissues were fully ground, the total protein was extracted by RIPA lysis. The protein concentration was detected by BCA (NC-BIO, LCB004). The protein concentration was adjusted to $4 \mu \mathrm{g} / \mu \mathrm{l}$. 12\% SDS-PAGE electrophoresis separation was carried out. The membrane was transferred to PVDF membrane after ionization and soaked with PBST for 5 min for washing. 5\% skim milk powder was used for sealing for $2 \mathrm{~h}$ and first antibody (1:1,000 Abcam, ab34164) was added for sealing overnight at $4^{\circ} \mathrm{C}$. The first antibody was removed by washing the film. Horseradish peroxidase-labeled sheep anti-mouse second antibody (1:5,000 LD, LD-BJ-101891) was added, incubated at $37^{\circ} \mathrm{C}$ for $1 \mathrm{~h}$ and rinsed 3 times with PBS for 5 min each time, and then developed in the darkroom. The excess liquid on the film was dried with a filter paper. The ECL was illuminated and developed. The protein bands were scanned and the gray values were analyzed in the Quantity One. Relative expression level of its protein $=$ the gray value of the target protein band $/$ the gray value of the $\beta$-actin protein band.

ELISA: Detection of renal injury indexes in rat blood. Renal function indexes include BUN, SCR, UA and $\beta 2-M G$. The detection was performed by using automatic biochemistry analyzer. Detection kit was BUN (Shanghai Kanglang Biological Technology Co., Ltd., KLJC0193), SCR (Shanghai Yuanye Biological Technology Co., Ltd., S83553), UA (Chundu Biological Technology Co., Ltd., CD-1161-LIN) and blood ß2-MG (SenBeiJia, SBJ-R0215).

Observation indexes. Levels of BUN, SCR, UA and $\beta 2-\mathrm{MG}$ of rats in four groups before and after injection. SDC-1 levels of rats in four groups after treatment.

Statistical methods. All the experimental results were statistically calculated by using SPSS 24.0 statistics (Shanghai Yuchuang Network Technology Co., Ltd.). Graphpad 8 (Shenzhen Tianruiqi Software Technology Co., Ltd.) was used to draw graphs and check the statistical calculation. The results of the experiments were all expressed in the form of (mean number \pm standard deviation). Single factor analysis of variance was used for comparison among groups. t-test was used for comparison between two groups of data conforming to normal distribution. Nonparametric test was used for data of non-normal distribution. Paired t-test was used for comparison before and after modeling. The difference was statistically significant at $\mathrm{P}<0.050$.

\section{Results}

Modeling results. Among the 50 rats, 25 were modeled and 1 died in MG. The success rate of modeling was $96 \%$.

Effect of GM6001 on SDC-1 expression in TG and TCG. The expression of SDC-1 protein in TG was 5.68 \pm 0.74 and it was the highest among the three groups $(\mathrm{P}<0.001)$. Expression of SDC-1 protein in CG was $1.49 \pm 0.34$, which was not significantly different from the expression of SDC-1 protein in TCG of $1.45 \pm 0.48(\mathrm{P}>0.050)$ and was significantly lower than that in the other two groups $(\mathrm{P}>0.001)$ (Fig. 1).

The levels of SDC-1 mRNA in TG were $54.39 \pm 5.34$ and it was also the highest among the three groups $(\mathrm{P}<0.001)$. The 
Table I. Primer sequences.

Upstream sequence (5'-3')

Downstream sequence (5'-3')

\begin{tabular}{lll}
\hline SDC-1 & CAGCAGCAACACCGAGAC & GATTGGCAGTTCCATCCTC \\
GAPDH & TGGCAAAGTGGAGATTGTT & CTTCTGGGTGGCAGTGAT
\end{tabular}

SDC-1, syndecan-1.

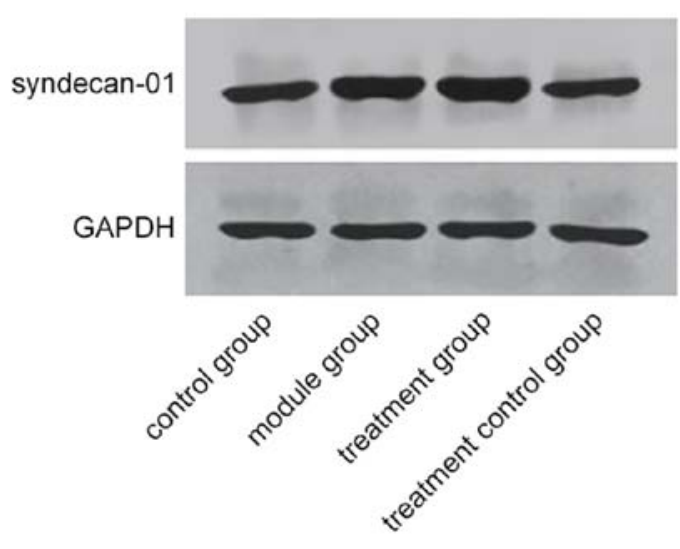

Figure 1. Detection results of western blotting.

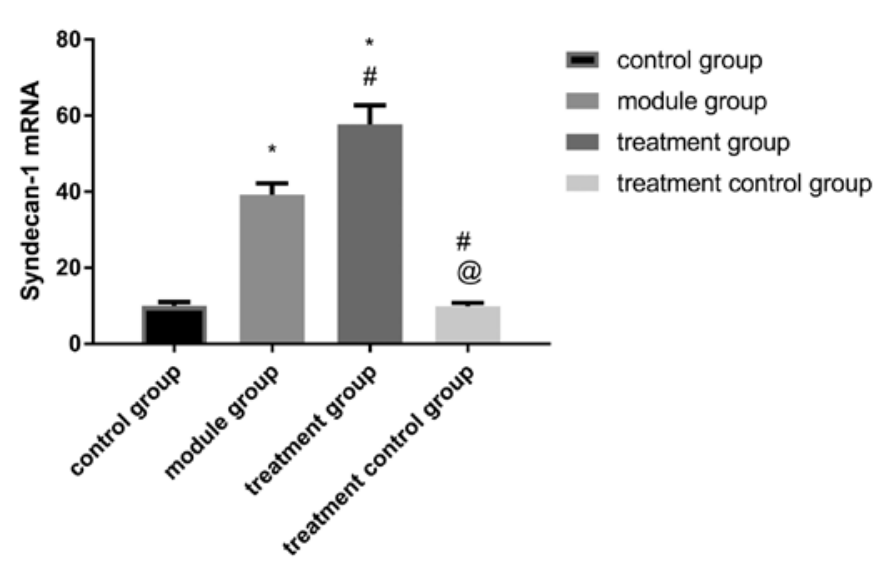

Figure 2. Detection of SDC-1 mRNA expression of rats in each group after treatment by qRT-PCR. ${ }^{*} \mathrm{P}<0.001$, compared with $\mathrm{CG}$; ${ }^{\text {} P} \mathrm{P}<0.001$, compared with MG; ${ }^{\circledR} \mathrm{P}<0.001$, compared with TG, SDC-1, syndecan-1. CG, control group; MG, module group; TG, treatment group.

levels of SDC-1 mRNA in CG was 9.74 1.39 , which was not significantly different from the levels of SDC-1 mRNA in TCG of $9.61 \pm 1.87(\mathrm{P}>0.050)$ and was lower than that in the other two groups $(\mathrm{P}>0.001)$ (Fig. 2).

Correlation between SDC-1 protein expression in tissues and SDC-1 mRNA levels in serum. Through Pearson correlation analysis of the relationship between SDC-1 protein expression in rat tissues and SDC-1 mRNA levels in serum of each group, it was found that SDC-1 protein expression in rat tissues was positively correlated with SDC-1 mRNA levels in serum (Fig. 3).
Changes of renal function indexes of rats in each group before and after treatment. There was no significant difference in BUN, SCR, UA and $\beta 2-\mathrm{MG}$ contents among the groups before modeling $(\mathrm{P}>0.05)$. Compared with before modeling, there was no significant difference in the contents of BUN, SCR, UA and $\beta 2-\mathrm{MG}$ between $\mathrm{CG}$ and TCG after modeling ( $\mathrm{P}>0.05)$. Compared with before modeling, the contents of BUN, SCR, $\mathrm{UA}$ and $\beta 2-\mathrm{MG}$ in $\mathrm{MG}$ and $\mathrm{TG}$ increased $(\mathrm{P}<0.05)$. After modeling, there was no significant difference between $\mathrm{CG}$ and TCG (P>0.050), while the contents of BUN, SCR, UA and $\beta 2-\mathrm{MG}$ in TG were significantly lower than those in MG and higher than those in $\mathrm{CG}$ and the TCG $(\mathrm{P}<0.05)$ (Table II).

\section{Discussion}

AKI is an extremely painful and costly disease that affects more than 13 million people each year, $85 \%$ of whom live in developing countries (10). However, the prevalence of acute kidney injury is also increasing in developed countries. The incidence rate is estimated to be as high as $15 \%$ in hospital patients and it is more common in severe patients, with the prevalence rate estimated to be as high as $60 \%$ (11). How to treat acute kidney injury is currently a major medical problem in the world.

SDC-1 is a member of the transmembrane sulfate acid heparin proteoglycan family. Through its sulfate acid heparin chain, SDC-1 covalently binds to a variety of extracellular ligands $(12,13)$. It mediates cell adhesion to several extracellular matrix molecules and promotes cell proliferation (14). Relevant reports have also proven that down-regulation of SDC-1 induces glomerular endothelial cell dysfunction by regulating the internalization of VEGFR-2, suggesting that SDC-1 may be a new target for the treatment of AKI (15). BUN and $\mathrm{Cr}$ are important indicators of the severity of renal function injury (16-18). The increase of $\beta 2-\mathrm{MG}$ in urine can predict residual renal function (19), which is currently the most commonly used renal function detection indicator in clinical and animal research and can reflect renal state to some extent. In this study, AKI rats were treated with different treatment methods and the expression of SDC-1 and renal function levels in rat kidney tissue were measured to explore the protective effect of GM6001 on the kidneys.

The results of this experiment showed that compared with $\mathrm{CG}$, the expression of SDC-1 protein and mRNA in MG were increased and the levels of renal function were decreased. The difference was statistically significant, indicating that SDC-1 participates in the development and progression of AKI. According to the study of de Melo Bezerra Cavalcante et al (20), the expression levels of SDC-1 in AKI 
Table II. Changes of renal function indexes before and after treatment.

\begin{tabular}{lccccrr}
\hline & CG & MG & TG & TCG & F & P-value \\
\hline Before modeling & & & & & & \\
BUN (mmol/l) & $5.32 \pm 1.39$ & $5.34 \pm 1.42$ & $5.38 \pm 1.37$ & $5.33 \pm 1.41$ & 0.004 & 0.999 \\
SCR $(\mu \mathrm{mmol} / \mathrm{l})$ & $85.52 \pm 6.34$ & $83.46 \pm 5.97$ & $83.48 \pm 6.51$ & $83.33 \pm 5.94$ & 0.002 & 0.999 \\
UA $(\mu \mathrm{mol} / \mathrm{l})$ & $128.45 \pm 14.37$ & $127.25 \pm 15.540$ & $127.32 \pm 12.53$ & $128.39 \pm 13.59$ & 0.024 & 0.995 \\
$\beta 2-M G(\mathrm{mg} / \mathrm{l})$ & $0.089 \pm 0.028$ & $0.090 \pm 0.027$ & $0.089 \pm 0.029$ & $0.087 \pm 0.029$ & 0.019 & 0.996 \\
After modeling & & & & & & \\
BUN $(\mathrm{mmol} / \mathrm{l})$ & $5.32 \pm 1.41$ & $12.53 \pm 2.52^{\mathrm{a}, \mathrm{d}}$ & $9.24 \pm 1.94^{\mathrm{a}, \mathrm{b}, \mathrm{d}}$ & $5.38 \pm 1.32^{\mathrm{b}, \mathrm{c}}$ & 33.600 & $<0.001$ \\
SCR $(\mu \mathrm{mmol} / \mathrm{l})$ & $83.63 \pm 6.39$ & $139.43 \pm 13.45^{\mathrm{a}, \mathrm{d}}$ & $114.50 \pm 16.35^{\mathrm{a}, \mathrm{b}, \mathrm{d}}$ & $83.47 \pm 5.45^{\mathrm{b}, \mathrm{c}}$ & 53.96 & $<0.001$ \\
UA $(\mu \mathrm{mol} / \mathrm{l})$ & $129.73 \pm 15.74$ & $198.35 \pm 31.53^{\mathrm{a}, \mathrm{d}}$ & $169.36 \pm 29.45^{\mathrm{a}, \mathrm{b}, \mathrm{d}}$ & $127.46 \pm 13.94^{\mathrm{b}, \mathrm{c}}$ & 19.470 & $<0.001$ \\
$\beta 2-M G(\mathrm{mg} / \mathrm{l})$ & $0.089 \pm 0.027$ & $0.213 \pm 0.059^{\mathrm{a}, \mathrm{d}}$ & $0.175 \pm 0.045^{\mathrm{a}, \mathrm{b}, \mathrm{d}}$ & $0.088 \pm 0.028^{\mathrm{b}, \mathrm{c}}$ & 22.130 & $<0.001$
\end{tabular}

${ }^{\mathrm{a}} \mathrm{P}<0.050$, compared with the $\mathrm{CG}$ at the same time; ${ }^{\mathrm{b}} \mathrm{P}<0.050$, compared with the MG at the same time; ${ }^{\mathrm{C}}<0.050$, compared with the $\mathrm{TG}$ at the same time; ${ }^{\mathrm{d}} \mathrm{P}<0.050$, compared with before treatment at the same group. BUN, blood urea nitrogen; SCR, serum, serum creatinine; UA, uric acid; $\beta 2-\mathrm{MG}, \beta 2$-microglobulin.

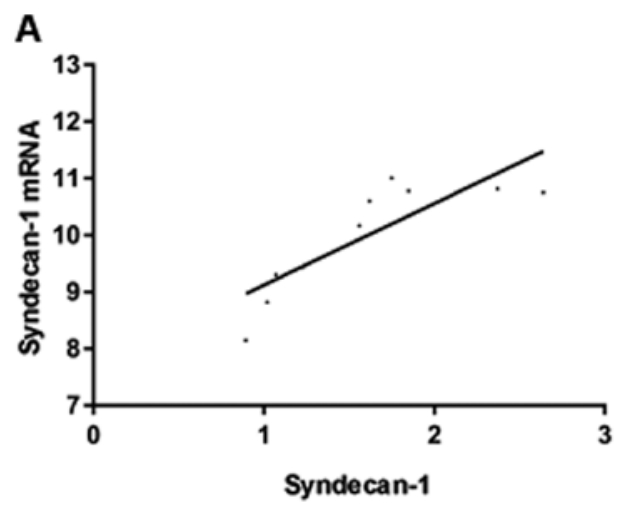

C

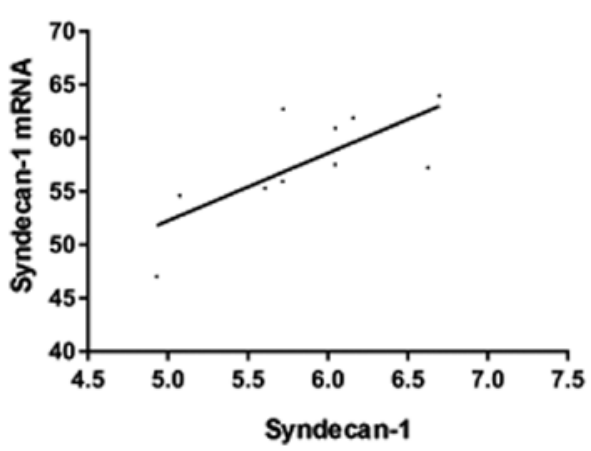

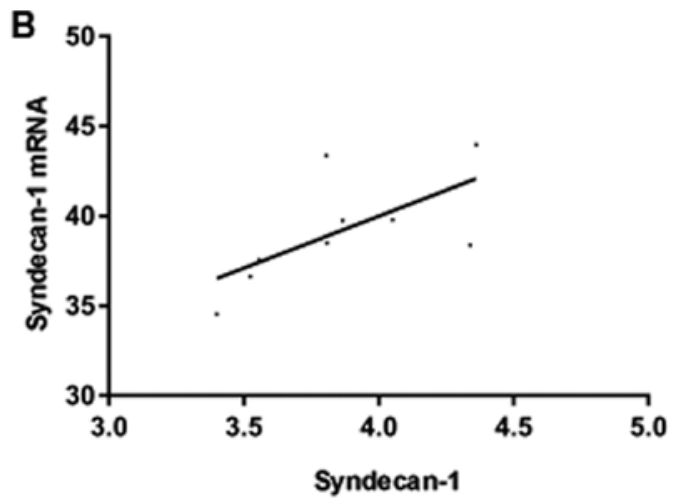

D

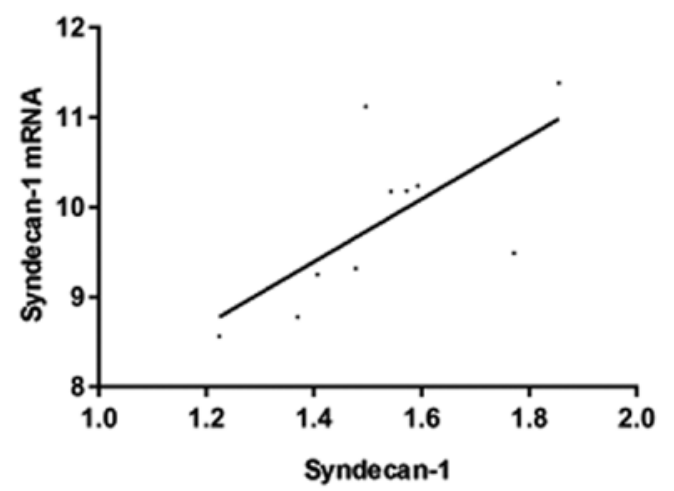

Figure 3. Correlation between SDC-1 protein expression in tissues and SDC-1 mRNA levels in serum. (A) SDC-1 protein expression in the control group (CG) was positively correlated with SDC-1 mRNA levels in serum ( $\mathrm{r}=0.838, \mathrm{P}=0.003)$. (B) SDC-1 protein expression in the model group was positively correlated with SDC-1 mRNA levels in serum $(\mathrm{r}=0.657, \mathrm{P}=0.031)$. (C) $\mathrm{SDC}-1$ protein expression in the treatment group (TG) was positively correlated with SDC-1 mRNA levels in serum $(\mathrm{r}=0.735, \mathrm{P}=0.015)$. (D) SDC-1 protein expression in the treatment of $\mathrm{CG}$ was positively correlated with SDC-1 mRNA levels in serum ( $\mathrm{r}=0.670$, $\mathrm{P}=0.027)$. SDC-1, syndecan-1.

caused by pediatric cardiac surgery were increased, which is approximately consistent with the results of this study. In studies of Mosaad et al on adolescent systemic lupus erythematosus patients (21), it was found that the serum levels of SDC-1 in patients were higher than that in healthy control group (CG), which can further support the results of this study. Our research also showed that the expression of SDC-1 protein in rat tissues was positively correlated with the levels of SDC-1 mRNA in serum, which further confirms the relationship between the two. However, we found that the SDC-1 content 
in TG was higher than that in MG and the renal function level in TG is better than that in MG, suggesting that the application of GM6001 before AKI can inhibit SDC-1 hydrolysis and has a protective effect on renal function level. However, there was no significant difference in renal function between TCG and $\mathrm{CG}$, which also indicated that GM6001 has no negative effect on renal function of rats and can be used for treatment of AKI. The reason is that soluble SDC- 1 can participate in the repair process of damaged tissues and promote the regeneration and repair of renal tubules when AKI occurs in the body (22). After the development of AKI, renal expression levels of MMP-2 and MMP-9 significantly increased (23), while matrix metalloproteinases such as MMP-7 (24) belong to hydrolase and participate in the down-regulation of SDC-1, thus reducing the levels of SDC-1 in the body and weakening the repair function of renal tissue. GM6001 has been proved to be able to inhibit MMP extensively (25). GM6001 changes the three-dimensional structure of the enzyme by binding with MMPs polypeptide to inhibit MMPs activity (26), reduce SDC-1 hydrolysis and to improve the renal protection role of SDC-1.

This study found that GM6001 can reduce SDC-1 hydrolysis by inhibiting MMP expression by establishing the AKI rat model. However, due to the short experimental period, the long-term effect of GM6001 on AKI were not observed. In this experiment, PCR was used for analysis. As the best quantitative detection method currently recognized in clinical practice, PCR is highly representative. In order to make the experimental data reliable, we used tissue testing, which can only be carried out when the rats were sacrificed. Therefore, no detailed multi-time point data was possible.

In conclusion, the increasing concentration of SDC-1 indicates that renal dysfunction is gradually aggravated. GM6001 can effectively improve renal function in rats after the treatment of AKI and is expected to become an effective drug for treating AKI.

\section{Acknowledgements}

Not applicable.

\section{Funding}

No funding was received.

\section{Availability of data and materials}

The datasets used and/or analyzed during the current study are available from the corresponding author on reasonable request.

\section{Authors' contributions}

$\mathrm{KZ}$ wrote the manuscript. KZ and RL conceived and designed the study. RL and GX were responsible for the collection and analysis of the experimental data. GX and $\mathrm{HH}$ interpreted the data and drafted the manuscript. LQ performed PCR, Western blot analysis and ELISA. KZ and LQ revised the manuscript critically for important intellectual content. All authors read and approved the final manuscript.

\section{Ethics approval and consent to participate}

The study was approved by the Ethics Committee of Weifang People's Hospital (Weifang, China).

\section{Patient consent for publication}

Not applicable.

\section{Conflict of interest}

The authors declare that they have no competing interests.

\section{References}

1. Bellomo R, Kellum JA and Ronco C: Acute kidney injury. Lancet 380: 756-766, 2012.

2. Vijayan A, Faubel S, Askenazi DJ, Cerda J, Fissell WH, Heung M, Humphreys BD, Koyner JL, Liu KD, Mour G, et al; American Society of Nephrology Acute Kidney Injury Advisory Group: Clinical use of the urine biomarker [TIMP-2]x[IGFBP7] for acute kidney injury risk assessment. Am J Kidney Dis 68: 19-28, 2016.

3. Szeto CC, Li PK, Johnson DW, Bernardini J, Dong J, Figueiredo AE, Ito Y, Kazancioglu R, Moraes T, Van Esch S, et al: ISPD catheter-related infection recommendations: 2017 update. Perit Dial Int 37: 141-154, 2017.

4. Doi K and Rabb H: Impact of acute kidney injury on distant organ function: Recent findings and potential therapeutic targets. Kidney Int 89: 555-564, 2016.

5. Mennerich D, Vogel A, Klaman I, Dahl E, Lichtner RB, Rosenthal A, Pohlenz HD, Thierauch KH and Sommer A: Shift of syndecan-1 expression from epithelial to stromal cells during progression of solid tumours. Eur J Cancer 40: 1373-1382, 2004.

6. Lu Z, Song N, Shen B, Xu X, Fang Y, Shi Y, Ning Y, Hu J, Dai Y, Ding X, et al: Syndecan-1 shedding inhibition to protect against ischemic acute kidney injury through HGF target signaling pathway. Transplantation 102: e331-e344, 2018.

7. Junior GS, Sobral D, Cavalcante MG, Meneses G, Martins A and Daher E: Novel biomarkers of kidney injury and endothelial dysfunction among HIV patients. Int J Infect Dis 73: 252, 2018.

8. Gill SE, Nadler ST, Li Q, Frevert CW, Park PW, Chen P and Parks WC: Shedding of syndecan-1/CXCL1 complexes by matrix metalloproteinase 7 functions as an epithelial checkpoint of neutrophil activation. Am J Respir Cell Mol Biol 55: 243-251, 2016.

9. Wang X, Zuo D, Chen Y, Li W, Liu R, He Y, Ren L, Zhou L, Deng T, Wang X, et al: Shed Syndecan-1 is involved in chemotherapy resistance via the EGFR pathway in colorectal cancer. $\mathrm{Br}$ J Cancer 111: 1965-1976, 2014.

10. Li F, Majd H, Weir MD, Arola DD and Xu HH: Inhibition of matrix metalloproteinase activity in human dentin via novel antibacterial monomer. Dent Mater 31: 284-292, 2015.

11. Makris K and Spanou L: Acute kidney injury: Definition, pathophysiology and clinical phenotypes. Clin Biochem Rev 37: 85-98, 2016.

12. Brauer R, Ge L, Schlesinger SY, Birkland TP, Huang Y, Parimon T, Lee V, McKinney BL, McGuire JK, Parks WC, et al: Syndecan-1 attenuates lung injury during influenza infection by potentiating c-met signaling to suppress epithelial apoptosis. Am J Respir Crit Care Med 194: 333-344, 2016.

13. Gandley RE, Althouse A, Jeyabalan A, Bregand-White JM, McGonigal S, Myerski AC, Gallaher M, Powers RW and Hubel CA: Low soluble syndecan-1 precedes preeclampsia. PLoS One 11: e0157608, 2016.

14. Götte M, Kersting C, Ruggiero M, Tio J, Tulusan AH, Kiesel L and Wülfing P: Predictive value of syndecan-1 expression for the response to neoadjuvant chemotherapy of primary breast cancer. Anticancer Res 26B: 621-627, 2006.

15. Jing Z, Wei-Jie Y, Yi-Feng ZG and Jing H: Downregulation of Syndecan-1 induce glomerular endothelial cell dysfunction through modulating internalization of VEGFR-2. Cell Signal 28: 826-837, 2016. 
16. Schmidt M, Mansfield KE, Bhaskaran K, Nitsch D, Sørensen HT, Smeeth L and Tomlinson LA: Serum creatinine elevation after renin-angiotensin system blockade and long term cardiorenal risks: cohort study. BMJ356: j791, 2017.

17. Zhang Z, Zhao J, Dong W, Remer E, Li J, Demirjian S, Zabell J and Campbell SC: Acute kidney injury after partial nephrectomy: Role of parenchymal mass reduction and ischemia and impact on subsequent functional recovery. Eur Urol 69: 745-752, 2016.

18. Tsuji T, Ohishi K, Takeda A, Goto D, Sato T, Ohashi N, Fujigaki Y, Kato A and Yasuda $\mathrm{H}$ : The impact of serum uric acid reduction on renal function and blood pressure in chronic kidney disease patients with hyperuricemia. Clin Exp Nephrol 22: 1300-1308, 2018.

19. Wong J, Sridharan S, Berdeprado J, Vilar E, Viljoen A, Wellsted D and Farrington K: Predicting residual kidney function in hemodialysis patients using serum $\beta$-trace protein and $\beta 2$-microglobulin. Kidney Int 89: 1090-1098, 2016.

20. de Melo Bezerra Cavalcante CT, Castelo Branco KM, Pinto Júnior VC, Meneses GC, de Oliveira Neves FM, de Souza NM, Penaforte KL, Martins AM and Libório AB: Syndecan-1 improves severe acute kidney injury prediction after pediatric cardiac surgery. J Thorac Cardiovasc Surg 152: 178-186. e2, 2016

21. Mosaad NA, Lotfy HM, Farag YM, Mahfouz RH and Shahin RM: Study of serum syndecan-1 levels in a group of Egyptian juvenile systemic lupus erythematosus patients. Immunol Lett 181: 16-19, 2017.
22. Kato M, Wang H, Kainulainen V, Fitzgerald ML, Ledbetter S, Ornitz DM and Bernfield M: Physiological degradation converts the soluble syndecan-1 ectodomain from an inhibitor to a potent activator of FGF-2. Nat Med 4: 691-697, 1998.

23. Xiong C, Zang X, Zhou X, Liu L, Masucci MV, Tang J, Li X, Liu N, Bayliss G, Zhao TC, et al: Pharmacological inhibition of Src kinase protects against acute kidney injury in a murine model of renal ischemia/reperfusion. Oncotarget 8: 31238-31253, 2017.

24. Zeng Y, Yao X, Chen L, Yan Z, Liu J, Zhang Y, Feng T, Wu J and Liu X: Sphingosine-1-phosphate induced epithelial-mesenchymal transition of hepatocellular carcinoma via an MMP-7/ syndecan-1/TGF- $\beta$ autocrine loop. Oncotarget 7: 63324-63337, 2016.

25. Dolmatov IY, Shulga AP, Ginanova TT, Eliseikina MG and Lamash NE: Metalloproteinase inhibitor GM6001 delays regeneration in holothurians. Tissue Cell 59: 1-9, 2019.

26. Liu X and Han Q: Efficacy of GM6001 as an adjuvant to ceftriaxone in a neonatal rat model of Streptococcus pneumoniae meningitis. Acta Neurobiol Exp (Wars) 74: 489-496, 2014. International (CC BY-NC-ND 4.0) License. 